\title{
Cerclage fixation without K-wires is associated with fewer complications and reoperations compared with tension band wiring in stable displaced olecranon fractures in elderly patients
}

\author{
Daniel Wenger ${ }^{1,2}$ (D) Gustav Cornefjord ${ }^{2} \cdot$ Cecilia Rogmark $^{1,2} \mathbb{D}$
}

Received: 24 November 2020 / Accepted: 23 June 2021 / Published online: 8 July 2021

(C) The Author(s) 2021

\begin{abstract}
Introduction Tension band wiring of olecranon fractures has high reported rates of complications and reoperations. We aimed to compare classic tension band wiring to cerclage fixation without K-wires in the treatment of displaced olecranon fractures in elderly patients. The primary outcome was reoperation. Secondary outcomes included complications and patient reported outcomes. Outcomes following non-operative treatment were also studied.

Materials and methods Patients aged $>69$ years presenting with Mayo class $2 \mathrm{a}$ and $2 \mathrm{~b}$ olecranon fractures at our institution from 2004 through $2016(n=239)$ were eligible for study. Fracture type, treatment method, complications and reoperations were assessed from radiographs and hospital files. QuickDASH surveys were collected by mail.

Results Patients operated with tension band wire technique had more reoperations ( $p$ value 0.03 ): relative risk (RR) 2.2 (CI 1.08-4.3), odds ratio (OR) 2.6 (CI 1.05-6.4), and complications ( $p$ value 0.001): RR 2.5 (CI 1.51-4.1), OR 3.7 (CI 1.67-8.2), compared with those operated with cerclage technique. Non-operative treatment yielded similar complication $(p$ value 0.2$)$ and reoperation rates ( $p$ value 0.06$)$ as cerclage fixation. The answer rate was insufficient to compare QuickDASH scores between treatments methods.

Conclusions In patients 70 years and older undergoing cerclage fixation for displaced stable olecranon fractures (Mayo class 2), the reoperation and complications rates were less than half of those in patients undergoing TBW fixation. Non-operative treatment yielded similar reoperation and complication rates to cerclage fixation, in selected cases.

Level of evidence III-retrospective comparative cohort study.
\end{abstract}

Keywords Olecranon $\cdot$ Fracture $\cdot$ Reoperation $\cdot$ Complication $\cdot$ Cerclage $\cdot$ Tension band wire

\section{Introduction}

Olecranon fractures account for one fifth of all proximal fractures of the forearm, and are commonly caused by low energy trauma in elderly patients [1].

Undisplaced olecranon fractures, Mayo class 1a and 1b, can be treated non-operatively $[2,3]$. Plate fixation is recommended for fractures with an unstable ulno-humeral joint (Mayo class 3a and 3b) [4].

Daniel Wenger

daniel.wenger@med.lu.se

1 Department of Orthopedics, Skåne University Hospital, Inga Marie Nilssons gata 22, 20502 Malmo, Sweden

2 Lund University, Lund, Sweden
Displaced but ulno-humerally stable olecranon fractures (Mayo class 2a and 2b) are commonly treated with either plate fixation or tension band wiring (TBW). TBW has high reported rates of local elbow complaints from surgical hardware, often necessitating reoperations [5-8]. Plate fixation, on the other hand, more frequently leads to serious complications compared with TBW [9]. A 2014 Cochrane review found no clear evidence favoring either method [10].

In light of the high complication risks with TBW and plate fixation, several studies suggest that non-operative treatment can be used also in class $2 \mathrm{a}$ and $2 \mathrm{~b}$ fractures in elderly patients [11-14].

Problems with skin protrusion and local elbow issues can occur if the $\mathrm{K}$-wires migrate $[6,15]$. At our institution, cerclage fixation without $\mathrm{K}$-wires has been an alternative to traditional TBW, since a previous study showed similar outcomes but a much lower reoperation frequency [7]. 
The aim of this study was to retrospectively compare cerclage fixation to TBW fixation with respect to reoperation rates (primary outcome), complication rates, and patient reported outcomes in elderly patients with Mayo class 2a and $2 \mathrm{~b}$ olecranon fractures. Another secondary aim was to study outcomes following non-operative treatment.

\section{Materials and methods}

All patients $>69$ years of age presenting with olecranon fractures at our institution from 2004 through 2016 were eligible for study. Patients were identified from a local registry of inhospital stays and outpatient visits using ICD-10-SE codes for olecranon fractures (S52.00 and S52.01) [16]. Fractures sustained before 2004 but operated during the study period were not included $(n=2)$.

Fractures were described according to the Mayo classification [2]. Only Mayo class 2 fractures, with $>2 \mathrm{~mm}$ displacement but without ulno-humeral instability, were included. Subdivision was made into 2 a (non-comminuted) and $2 b$ (comminuted) (Fig. 1).

In total, 376 patients with olecranon fractures were identified, 263 of whom had Mayo class 2 fractures. After exclusion of 4 subjects with pre-existing elbow arthroplasty, 8 with bilateral fractures or a second ipsilateral fracture during the study period, and 12 with missing data, 239 subjects were included (Fig. 2).

Treatment methods were divided in TBW, cerclage fixation (using one or two cerclages), plate fixation (including combined plate and cerclage), and non-operative (Fig. 1). The primary aim of the study was to compare TBW with cerclage fixation with regard to unplanned return to theatre. Plate fixation is not standard practice for Mayo class 2 fractures, and non-operative treatment is typically reserved for elderly infirm patients at our clinic, introducing risk of selection bias in such cases. However, patients matching inclusion criteria and treated with these methods were also evaluated,
Fig. 1 a Pre-operative lateral radiograph of a Mayo class $2 \mathrm{a}$ olecranon fracture. b Tension band wiring. Intraoperative lateral radiograph of the fracture in a after reduction and tension band wire fixation. The cerclage is proximally anchored in the bend of the K-wires. $\mathbf{c}$ Pre-operative lateral radiograph of a Mayo class 2 b olecranon fracture. There is a depressed central fragment (arrow). d Cerclage fixation. Intraoperative lateral radiograph of the fracture in $\mathbf{c}$ after open reduction and fixation with two cerclages. The cerclages are in figure- 8 and figure- 0 configuration, respectively, and are proximally anchored in the triceps tendon

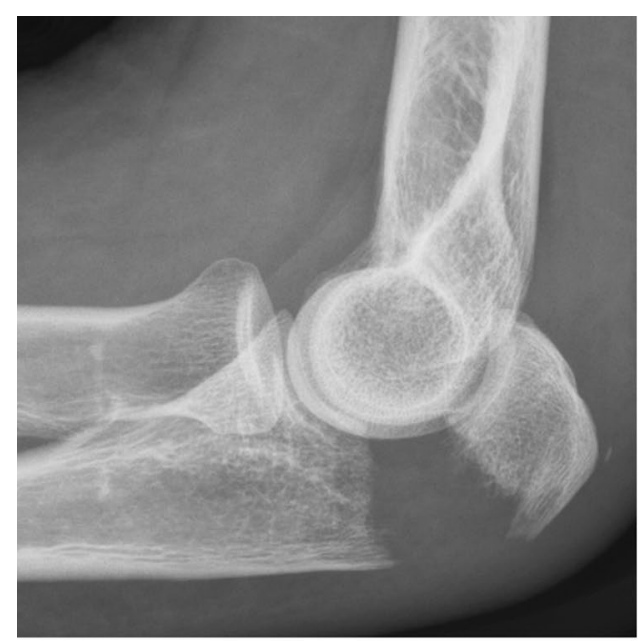

a

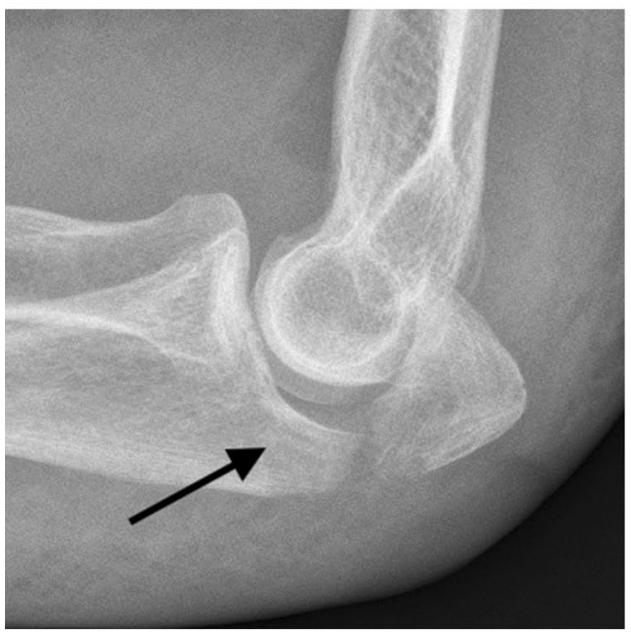

C

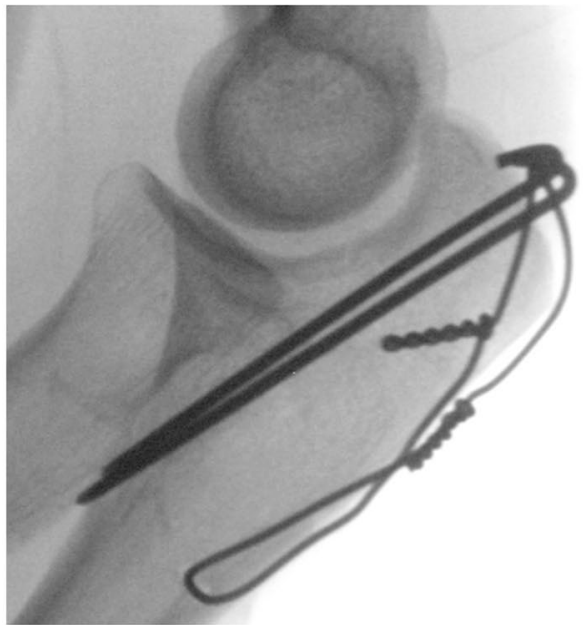

b

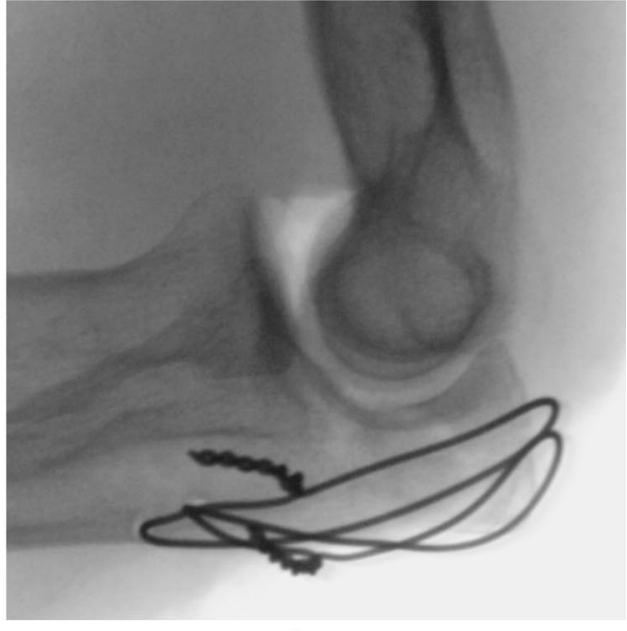

d 
Fig. 2 Exclusion flowchart

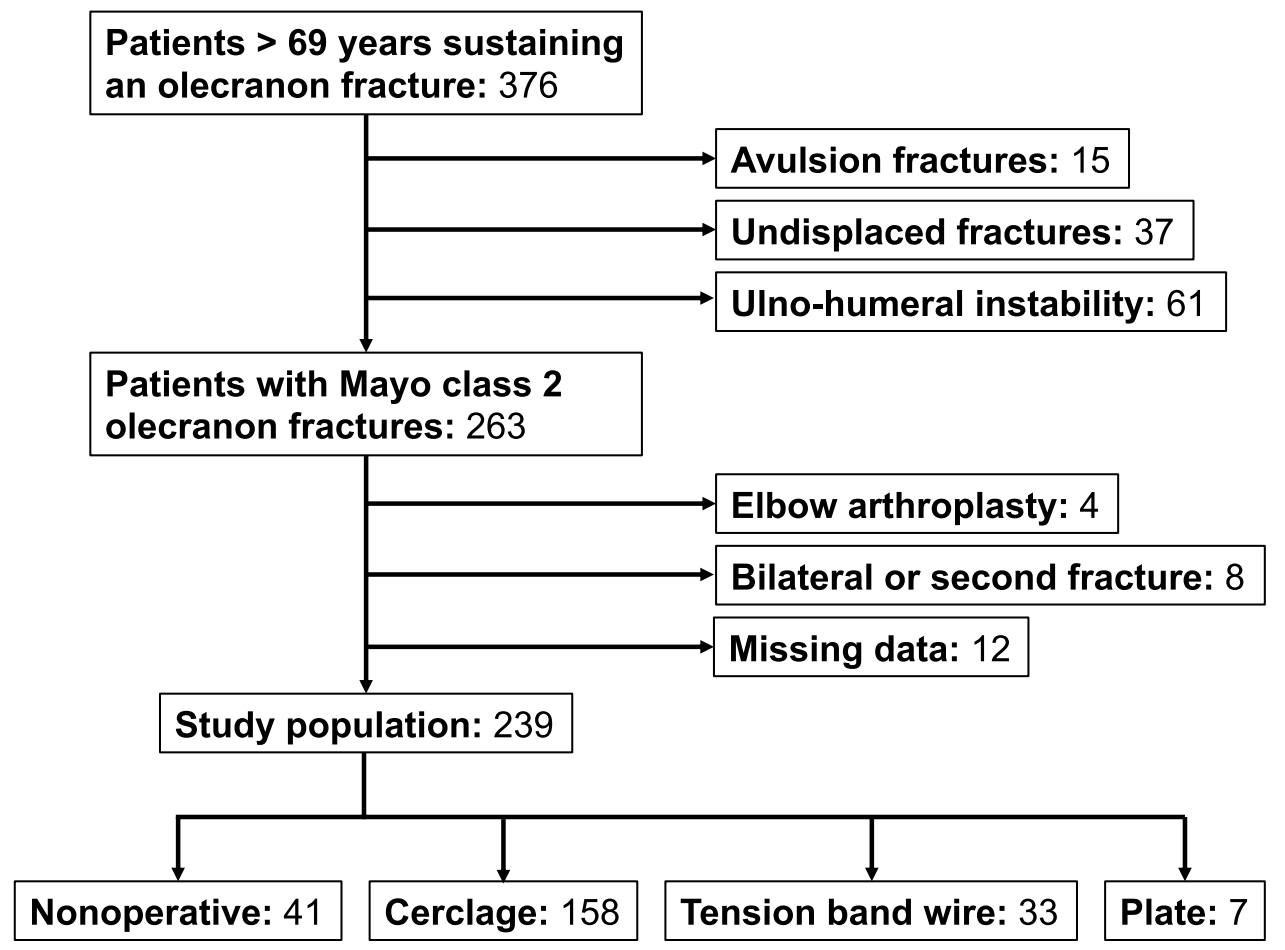

both to give a complete view of treatment given in this age group, and to report patient related outcome after non-operative treatment compared to surgical treatment, which has not been done previously. Complications and patient reported outcomes were secondary study outcomes. The choice of treatment method was at the surgeon's discretion. The postoperative protocol most commonly included 3 weeks in an elbow plaster cast, followed by active motion exercises, and gradually progressive weight bearing approximately from 6 weeks post-operatively. At the time of cast removal, patients met the treating physician (or if unavailable, another orthopaedic surgeon at the trauma service of the clinic), and a physiotherapist. In uneventful cases, rehabilitation was then given and followed by the physiotherapist. Postoperative radiographs were obtained if there was any clinical problem, or if the quality of intra-operative radiographs (often including stability provocation) was poor.

Data on reoperations, complications, and soft tissue integrity (open or closed fracture) were obtained from hospital files. A complication was defined as any complaint related to the fracture, leading to a health-care visit, or any deviation from the expected clinical course. Complications were classified as local elbow issues, sensory disturbances, severely impaired range of motion, infection or "other". Infections were classified according to Dindo et al. not subdividing into A and B sublevels [17]. Reoperations were classified by underlying cause (local elbow issues, infection or "other").

Patient-reported outcomes were evaluated using the QuickDASH score [18]. A difference of 12 points on the
QuickDASH score was considered clinically important [19]. Questionnaires were sent by mail, together with a letter of consent, to the 107 subjects alive at follow-up.

The median time to follow-up was 5.2 years (IQR: 2.6-8.1) for surgically treated patients. In surgically treated patients who died during follow-up, the median time to death was 3.5 years (IQR: 1.8-6.4). The time of death was not available for non-surgically treated patients.

\section{Statistics}

Comparisons of categorical variables were performed with the Chi-square test. The Mann-Whitney $U$ test was used for group comparisons of continuous variables. Nonparametric tests were used as the continuous variables under investigation, age and QuickDASH, were not normally distributed (the Shapiro Wilk W-statistic yielded $p$ values $<0.05)$. Data were presented as medians with interquartile range (IQR), as it was not normally distributed. Absolute risks with $95 \%$ confidence intervals (CI) were calculated using binomial distribution (exact method). Relative risks and numbers needed to harm with $95 \%$ confidence intervals (CI) were calculated according to Altman [20, 21].

For all analyses, an alpha level of 0.05 was considered statistically significant. Statistical analyses were performed using SPSS statistics for Macintosh (Armonk; NY; IBM corp.). 


\section{Results}

In the 239 included cases, the male to female ratio was 1:4.5. There were nine (4\%) open fractures. Cerclage wiring was the most frequently used treatment method $(n=158)$, followed by non-operative treatment $(n=41)$, TBW $(n=33)$ and plate fixation $(n=7)$. A total of 73 surgeons performed 189 of the 198 operations (in 9 cases: 5 TBW and 4 plates, information was missing). Eleven surgeons performed five or more operations each.

In $32(13 \%)$ cases, unplanned secondary surgery was performed (Table 1). The reoperation rate was not significantly affected by sex, or whether the fracture was comminuted or open. Patients undergoing reoperation were slightly younger (median age 78 vs. 82 years, $p$ value 0.02$)$. Patients treated with cerclage were less likely to undergo reoperation ( $p$ value 0.03 ): $13 \%$ (20 of 158), compared with TBW: $27 \%$ (9 of 33). The relative risk of undergoing secondary surgery was $2.2(1.08-4.3)$ after TBW compared to cerclage fixation. The number needed to harm was 6.8 (3.6-76). Differences in reoperation rates were not statistically significant comparing cerclage fixation to non-operative treatment, or plate fixation.

A total of $52(22 \%)$ patients had complications (Table 2). The complication rate was not significantly
Table 1 Patients with no secondary surgery compared with patients who underwent secondary surgery
Table 2 Patients with uneventful healing compared with patients with complications

\begin{tabular}{|c|c|c|c|c|c|}
\hline & Total & No secondary surgery & Secondary surgery & $p$ value & Relative risk $(95 \% \mathrm{CI})^{\mathrm{a}}$ \\
\hline Female & 196 & $171(87 \%)$ & $25(13 \%)$ & 0.5 & - \\
\hline Male & 43 & $36(84 \%)$ & $7(16 \%)$ & & - \\
\hline Age, years ${ }^{b}$ & - & $82(77-88)$ & $78(73-84)$ & 0.02 & - \\
\hline Mayo 2a & 139 & $118(85 \%)$ & $21(15 \%)$ & 0.4 & - \\
\hline Mayo $2 b$ & 100 & $89(89 \%)$ & $11(11 \%)$ & & - \\
\hline Open fracture & 9 & $9(100 \%)$ & 0 & 0.2 & - \\
\hline Non-operative & 41 & $40(98 \%)$ & $1(2 \%)$ & $0.06^{\mathrm{c}}$ & $0.19(0.03-1.39)$ \\
\hline Cerclage wire $^{\mathrm{d}}$ & 158 & $138(87 \%)$ & $20(13 \%)$ & - & - \\
\hline Tension band wire & 33 & $24(73 \%)$ & $9(27 \%)$ & $0.03^{\mathrm{c}}$ & $2.2(1.08-4.3)$ \\
\hline Plate & 7 & $5(71 \%)$ & $2(29 \%)$ & $0.2^{\mathrm{c}}$ & $2.3(0.65-7.8)$ \\
\hline
\end{tabular}

Patients returning to theatre were more likely to have been operated with tension band wiring compared with those with cerclage fixation. Data given as frequency (\%) unless otherwise stated

${ }^{a}$ Relative risk (95\% CI) from comparison with cerclage fixation

${ }^{\mathrm{b}}$ Data given as median (interquartile range)

${ }^{c} p$ value from comparison with cerclage fixation

${ }^{\mathrm{d}}$ Of which 85 cases were operated with 1 cerclage, and 73 cases with 2 cerclages

\begin{tabular}{|c|c|c|c|c|c|}
\hline & Total & Uneventful healing & Complication & $p$ value & Relative risk $(95 \% \mathrm{CI})^{\mathrm{a}}$ \\
\hline Female & 196 & $153(78 \%)$ & $43(22 \%)$ & 0.9 & - \\
\hline Male & 43 & $34(79 \%)$ & $9(21 \%)$ & & - \\
\hline Age, years ${ }^{b}$ & - & $82(77-88)$ & $80(75-86)$ & 0.09 & - \\
\hline Mayo 2a & 139 & $112(81 \%)$ & $27(19 \%)$ & 0.3 & - \\
\hline Mayo 2b & 100 & $75(75 \%)$ & $25(25 \%)$ & & - \\
\hline Open fracture & 9 & $7(78 \%)$ & $2(22 \%)$ & 1 & - \\
\hline Non-operative & 41 & $37(90 \%)$ & $4(10 \%)$ & $0.2^{\mathrm{c}}$ & $0.53(0.20-1.43)$ \\
\hline Cerclage $^{\mathrm{d}}$ & 158 & $129(82 \%)$ & $29(18 \%)$ & - & - \\
\hline Tension band wire & 33 & $18(55 \%)$ & $15(45 \%)$ & $0.001^{\mathrm{c}}$ & $2.5(1.51-4.1)$ \\
\hline Plate & 7 & $3(43 \%)$ & $4(57 \%)$ & $0.04^{\mathrm{c}}$ & $3.1(1.51-6.4)$ \\
\hline
\end{tabular}

Patients with complications were more likely to have been operated with tension band wiring or plate fixation, compared with those with cerclage fixation. Data given as frequency (\%) unless otherwise stated

${ }^{a}$ Relative risk (95\% CI) from comparison with cerclage fixation

${ }^{\mathrm{b}}$ Data given as median (interquartile range)

${ }^{c} p$ value from comparison with cerclage fixation

${ }^{\mathrm{d}}$ Of which 85 cases were operated with 1 cerclage, and 73 cases with 2 cerclages 
affected by sex, age, or whether the fracture was comminuted, or open. Patients treated with cerclage had an $18 \%$ (29 of 158) complication rate, which was lower than TBW ( $p$ value 0.001 ): $45 \%$ (15 of 33), relative risk 2.5 (1.51-4.1), or plate fixation ( $p$ value 0.04 ): $57 \%$ (4 of 7), relative risk 3.1 (1.51-6.4), and similar to non-operative treatment: $9.8 \%$ (4 of 41), relative risk $0.53(0.20-1.43)$. The number needed to harm for TBW, compared to cerclage fixation, was 3.7 (2.4-8.5). Local soft-tissue problems were the most common complication, and the most common cause for reoperation (Table 3). Patients in the TBW group had local issues more often than those in the cerclage group ( $p$ value 0.01 ), and had a tripled risk of undergoing reoperation for this cause ( $p$ value 0.007 ) There were five cases of pseudarthrosis $(3.2 \%)$ in the cerclage group, including one early secondary displacement and one occurring after implant removal due to infection, and one pseudarthrosis (3.0\%) occurring after implant removal due to infection in the TBW group.

Complications and reoperations are listed in Table 3. There were 21 infections in total, Dindo class 1-4: 11, two, seven, and one, respectively. The patient with a class 4 complication developed sepsis with endocarditis, secondary to a wound infection. The infection rate did not significantly differ between the TBW group: $12 \%$, and the cerclage group: $8 \%$ ( $p$ value 0.7 ).

There was a large spread in QuickDASH scores, with inadequate sample size $(n=41)$ to demonstrate any difference in patient reported outcome between treatment methods (28 responses from the cerclage group, 7 from the TBW group, and 3 from non-operatively treated and plate fixated, respectively).

\section{Discussion}

In this cohort of elderly patients, cerclage fixation without $\mathrm{K}$-wires was associated with fewer reoperations and complications compared with classical TBW. In an experimental setting, both fixation methods result in similar load-to-failure resistance [22]. The only previous clinical study comparing cerclage fixation to TBW also found a roughly doubled risk of reoperation with TBW, although the absolute risks were three times higher compared to our findings [7]. That investigation was performed at the same department, and we believe our results to better reflect the current situation with a higher threshold to hardware removal. A small case series of cerclage fixation without K-wires reported hardware removal in 4 of 17 patients, and good clinical outcomes at almost 5-year follow-up [23]. Another paper describing a similar technique with non-absorbable sutures also reported a low reoperation rate, although only 17 fractures and 11 osteotomies were included and the follow-up time was not specified [24]. Studies on TBW in olecranon fractures report reoperation rates between 22 and $82 \%$, and complication rates between 23 and 63\% [5, 6, 8, 9, 25-27].

Our finding of a lower all-cause complication rate in patients treated with cerclage (18\%), compared with TBW (45\%), has not been previously reported to our knowledge. The most common complication was local soft-tissue
Table 3 Comparison of treatment methods

\begin{tabular}{|c|c|c|c|c|}
\hline & Non-operative & Cerclage & Tension band wire & Plate \\
\hline Age, years ${ }^{\mathrm{a}}$ & $88(83-90)$ & $81(77-86)$ & $77(75-82)$ & $78(70-88)$ \\
\hline Mayo class, 2b/2a & $20 / 21(49 \%)$ & $63 / 95(40 \%)$ & $13 / 20(39 \%)$ & $4 / 3(57 \%)$ \\
\hline Open fracture & $1(2 \%)$ & $8(5 \%)$ & 0 & 0 \\
\hline Reoperation due to infection & $1(2 \%)$ & $4(3 \%)$ & $2(6 \%)$ & $2(29 \%)$ \\
\hline Reoperation due to local issues & 0 & $13(8 \%)$ & $8(24 \%)$ & 0 \\
\hline Reoperation due to other causes & 0 & $3(2 \%)^{b}$ & 0 & 0 \\
\hline Local issues & 0 & $17(11 \%)$ & $9(27 \%)$ & 0 \\
\hline Sensory deficits & $1(2 \%)$ & 0 & $1(3 \%)$ & 0 \\
\hline Infections & $3(7 \%)$ & $12(8 \%)$ & $4(12 \%)$ & $2(29 \%)$ \\
\hline Other complications & $1(2 \%)$ & $12(8 \%)$ & $5(15 \%)$ & $1(14 \%)$ \\
\hline Complications, patients $^{\mathrm{c}}$ & $4(10 \%)$ & $29(18 \%)$ & $15(45 \%)$ & $4(57 \%)$ \\
\hline Secondary surgery, patients ${ }^{\mathrm{d}}$ & $1(2 \%)$ & $20(13 \%)$ & $9(27 \%)$ & $2(29 \%)$ \\
\hline
\end{tabular}

Patient characteristics, complications, and outcomes in 239 Mayo class $2 \mathrm{a}$ and $2 \mathrm{~b}$ fractures. Data given as frequency (\% within method) unless otherwise stated

${ }^{a}$ Data given as median (interquartile range)

${ }^{b}$ Other causes for reoperation include two cases of pseudarthrosis, and one case of posttraumatic osteoarthritis treated with total elbow arthroplasty

${ }^{c} p$ values for comparisons between methods are given in Table 2

${ }^{\mathrm{d}} p$ values for comparisons between methods are given in Table 1 
problems, and this occurred more often in the TBW group. Soft-tissue issues was also the main driver behind the high reoperation frequency in the TBW group, and behind the difference found between the study groups. K-wires can migrate and protrude under or through the skin [15]. In this study, we did not specifically assess the rate of K-wire migration.

The low number of patients with plate fixation in this cohort limits our ability to draw conclusions, even though the risk of complication or reoperation was three times higher following plating compared with cerclage fixation. At our institution, plate fixation is mainly used for unstable olecranon fractures (Mayo 3a and 3b). A prospective randomised trial comparing plate fixation to TBW reported lower complication rates in general (38 vs. 63\%), but a higher frequency of serious complications in the plate group [9]. A previous meta-analysis, mainly including retrospective studies, also found a lower overall complication risk with plating compared with TBW [28].

In contrast to plate fixation and TBW, non-operative treatment yielded similar rates of complications and reoperations to cerclage fixation. However, the indication for non-operative treatment of a displaced olecranon fracture at our institution was a patient deemed too fragile to undergo surgery or patient refusal, introducing selection bias, including bias against secondary surgery. In this elderly cohort, 41 (17\%) of 239 patients were deemed too frail for anaesthesia and surgery, or refused such treatment. That group of patients obviously differ from those who were operated, which is evident also from their median age of 88 years, so comparisons between them and surgically treated patients have to be made with caution. Previous studies, including one prospective randomised trial, have indicated that non-operative treatment can be a valid option for elderly patients with displaced, but stable, olecranon fractures [11-14]. Such patients often seem to accept the functional outcome of a non-union, which affects four out of every five patients who are treated nonoperatively $[12,13,29]$.

We included the validated upper extremity outcome measure QuickDASH in an effort to study patients' perceptions, which may ultimately be the most relevant outcome. In this elderly cohort, where a significant proportion of the patients died before follow-up, the low response rate limited the analysis of differences in QuickDASH scores between treatment methods. Nevertheless, patient-reported outcomes and satisfaction are important measures that should be included in future studies. They should ideally be collected both at short-term and long-term follow-up.

There is a possibility of selection bias in the study groups, which limits the strength of our conclusions. Still, as patients treated with cerclage and TBW did not differ with regard to age, sex, Mayo class, or soft-tissue integrity, we believe that our main results most likely reflect differences between the two surgical methods. We believe the main determinant of treatment choice in this cohort was surgeon preference to, or familiarity with, either method. It is also possible that our results are not generalisable to some subgroup of patients. Our data could be used for calculating adequate sample sizes for hypothesis testing studies, with a higher level of evidence which is needed to give solid evidence-based treatment recommendations.

We did not have any reliable data on smoking status, a known risk factor for reoperations and complications. Tobacco use should preferably be controlled for in any prospective clinical trial of surgical treatments [30]. It is possible that some study participant was treated for a complication elsewhere which could have been missed, but as our department serves a geographical catchment area with no other hospital treating fractures (for primary treatment), and is the referral center (including the orthoplastic service) for orthopaedic surgery for all bordering geographic areas, we think it is unlikely that a significant number of such missed complications could have occurred. One should also be careful about generalizing our findings to younger patients, as poor bone quality in the elderly may increase the risk of $\mathrm{K}$-wire migration.

\section{Conclusions}

In patients 70 years and older undergoing cerclage fixation for displaced stable olecranon fractures (Mayo class 2), the reoperation and complications rates were less than half of those in patients undergoing TBW fixation. Non-operative treatment yielded similar reoperation and complication rates to cerclage fixation, in selected cases.

Author contributions All authors took part in study design. GC collected the data and performed statistical analyses under guidance from DW and CR. DW wrote the manuscript. All authors revised the manuscript.

Funding Open access funding provided by Lund University. The study was supported by a grant from Lund University Hospital Funds. The funding agent had no role in the study design; in the collection, analysis and interpretation of data; in the writing of the report; or in the decision to submit the article for publication.

Data availability Study data can be made available upon reasonable request to the corresponding author.

\section{Declarations}

Conflict of interest The authors declare no relevant financial or nonfinancial interests. 
Ethical approval The study was approved by the regional ethics committee (Lund University 2017/1054, date of issue: 2018-01-30) and performed in compliance with the 1964 Declaration of Helsinki.

Consent to participate Obtaining consent to participate in this retrospective study was not deemed necessary by the ethical review board.

Open Access This article is licensed under a Creative Commons Attribution 4.0 International License, which permits use, sharing, adaptation, distribution and reproduction in any medium or format, as long as you give appropriate credit to the original author(s) and the source, provide a link to the Creative Commons licence, and indicate if changes were made. The images or other third party material in this article are included in the article's Creative Commons licence, unless indicated otherwise in a credit line to the material. If material is not included in the article's Creative Commons licence and your intended use is not permitted by statutory regulation or exceeds the permitted use, you will need to obtain permission directly from the copyright holder. To view a copy of this licence, visit http://creativecommons.org/licenses/by/4.0/.

\section{References}

1. Duckworth AD, Clement ND, Aitken SA, Court-Brown CM, McQueen MM (2012) The epidemiology of fractures of the proximal ulna. Injury 43:343-346. https://doi.org/10.1016/j.injury. 2011.10.017

2. Morrey BF (1995) Current concepts in the treatment of fractures of the radial head, the olecranon, and the coronoid. Instr Course Lect 44:175-185

3. Newman SD, Mauffrey C, Krikler S (2009) Olecranon fractures. Injury 40:575-581. https://doi.org/10.1016/j.injury.2008.12.013

4. Hak DJ, Golladay GJ (2000) Olecranon fractures: treatment options. J Am Acad Orthop Surg 8:266-275. https://doi.org/10. 5435/00124635-200007000-00007

5. Chalidis BE, Sachinis NC, Samoladas EP, Dimitriou CG, Pournaras JD (2008) Is tension band wiring technique the "gold standard" for the treatment of olecranon fractures? A long term functional outcome study. J Orthop Surg Res 3:9. https://doi.org/10. 1186/1749-799x-3-9

6. Claessen FM, Braun Y, Peters RM, Dyer G, Doornberg JN, Ring D (2016) Factors associated with reoperation after fixation of displaced olecranon fractures. Clin Orthop Relat Res 474:193-200. https://doi.org/10.1007/s11999-015-4488-2

7. Karlsson MK, Hasserius R, Besjakov J, Karlsson C, Josefsson PO (2002) Comparison of tension-band and figure-of-eight wiring techniques for treatment of olecranon fractures. J Shoulder Elbow Surg 11:377-382. https://doi.org/10.1067/mse.2002.124548

8. Romero JM, Miran A, Jensen CH (2000) Complications and reoperation rate after tension-band wiring of olecranon fractures. J Orthop Sci 5:318-320. https://doi.org/10.1007/s007760000 050318.776

9. Duckworth AD, Clement ND, White TO, Court-Brown CM, McQueen MM (2017) Plate versus tension-band wire fixation for olecranon fractures: a prospective randomized trial. J Bone Jt Surg Am 99:1261-1273. https://doi.org/10.2106/jbjs.16.00773

10. Matar HE, Ali AA, Buckley S, Garlick NI, Atkinson HD (2014) Surgical interventions for treating fractures of the olecranon in adults. Cochrane Database Syst Rev. https://doi.org/10.1002/ 14651858.CD010144.pub2

11. Duckworth AD, Clement ND, McEachan JE, White TO, CourtBrown CM, McQueen MM (2017) Prospective randomised trial of non-operative versus operative management of olecranon fractures in the elderly. Bone Jt J 99-b:964-972. https://doi.org/10.1302/ 0301-620x.99b7.Bjj-2016-1112.R2

12. Gallucci GL, Piuzzi NS, Slullitel PA, Boretto JG, Alfie VA, Donndorff A, De Carli P (2014) Non-surgical functional treatment for displaced olecranon fractures in the elderly. Bone Jt J 96-b:530-534. https://doi.org/10.1302/0301-620x.96b4.33339

13. Marot V, Bayle-Iniguez X, Cavaignac E, Bonnevialle N, Mansat P, Murgier J (2018) Results of non-operative treatment of olecranon fracture in over 75-year-olds. Orthop Traumatol Surg Res 104:79-82. https://doi.org/10.1016/j.otsr.2017.10.015

14. Veras Del Monte L, Sirera Vercher M, Busquets Net R, Castellanos Robles J, Carrera Calderer L, Mir Bullo X (1999) Conservative treatment of displaced fractures of the olecranon in the elderly. Injury 30(105-110):105-110. https://doi.org/10.1016/ s0020-1383(98)00223-x

15. Saeed ZM, Trickett RW, Yewlett AD, Matthews TJ (2014) Factors influencing K-wire migration in tension-band wiring of olecranon fractures. J Shoulder Elbow Surg 23:1181-1186. https://doi.org/ 10.1016/j.jse.2014.02.018

16. Socialstyrelsen (2010) Internationell statistisk klassifikation av sjukdomar och relaterade hälsoproblem: (ICD-10-SE). Systematisk förteckning. Svensk version. (Swedish version). Socialstyrelsen, Stockholm

17. Dindo D, Demartines N, Clavien PA (2004) Classification of surgical complications: a new proposal with evaluation in a cohort of 6336 patients and results of a survey. Ann Surg 240:205-213. https://doi.org/10.1097/01.sla.0000133083.54934.ae

18. Beaton DE, Wright JG, Katz JN (2005) Development of the quickdash: comparison of three item-reduction approaches. J Bone Jt Surg Am 87:1038-1046. https://doi.org/10.2106/jbjs.D.02060

19. Iordens GIT, Den Hartog D, Tuinebreijer WE, Eygendaal D, Schep NWL, Verhofstad MHJ, Van Lieshout EMM (2017) Minimal important change and other measurement properties of the Oxford elbow score and the quick disabilities of the arm, shoulder, and hand in patients with a simple elbow dislocation; validation study alongside the multicenter funcsie trial. PLoS ONE 12:e0182557. https://doi.org/10.1371/journal.pone.0182557

20. Altman DG (1991) Practical statistics for medical research. Chapman and Hall, London

21. Altman DG (1998) Confidence intervals for the number needed to treat. BMJ 317:1309-1312. https://doi.org/10.1136/bmj.317. 7168.1309

22. Murphy DF, Greene WB, Gilbert JA, Dameron TB Jr (1987) Displaced olecranon fractures in adults. Biomechanical analysis of fixation methods. Clin Orthop Relat Res 224:210-214

23. Roukoz S, Bayoud W (2016) Wireless tension band wiring for olecranon fractures. Case Series. J Med Liban 64:160-163. https://doi.org/10.12816/0031525

24. Phadnis J, Watts AC (2017) Tension band suture fixation for olecranon fractures. Shoulder Elbow 9:299-303. https://doi.org/10. $1177 / 1758573216687305$

25. Powell AJ, Farhan-Alanie OM, McGraw IWW (2019) Tension band wiring versus locking plate fixation for simple, two-part Mayo 2A olecranon fractures: a comparison of post-operative outcomes, complications, reoperations and economics. Musculoskelet Surg 103:155-160. https://doi.org/10.1007/s12306-018-0556-6

26. Liu QH, Fu ZG, Zhou JL, Lu T, Liu T, Shan L, Liu Y, Bai L (2012) Randomized prospective study of olecranon fracture fixation: cable pin system versus tension band wiring. J Int Med Res 40:1055-1066. https://doi.org/10.1177/147323001204000324

27. Snoddy MC, Lang MF, An TJ, Mitchell PM, Grantham WJ, Hooe BS, Kay HF, Bhatia R, Thakore RV, Evans JM, Obremskey WT, Sethi MK (2014) Olecranon fractures: factors influencing re-operation. Int Orthop 38:1711-1716. https://doi.org/10.1007/ s00264-014-2378-y 
28. Ren YM, Qiao HY, Wei ZJ, Lin W, Fan BY, Liu J, Li A, Kang Y, Liu S, Hao Y, Zhou XH, Feng SQ (2016) Efficacy and safety of tension band wiring versus plate fixation in olecranon fractures: a systematic review and meta-analysis. J Orthop Surg Res 11:137. https://doi.org/10.1186/s13018-016-0465-Z

29. Duckworth AD, Bugler KE, Clement ND, Court-Brown CM, McQueen MM (2014) Nonoperative management of displaced olecranon fractures in low-demand elderly patients. J Bone Jt Surg Am 96:67-72. https://doi.org/10.2106/jbjs.L.01137
30. Scolaro JA, Schenker ML, Yannascoli S, Baldwin K, Mehta S, Ahn J (2014) Cigarette smoking increases complications following fracture: a systematic review. J Bone Jt Surg Am 96:674-681

Publisher's Note Springer Nature remains neutral with regard to jurisdictional claims in published maps and institutional affiliations. 